\title{
Towards Quality Art Education: Challenges and Opportunities
}

\author{
*Ivan Emeka Okonkwo \\ http://dx.doi.org/10.4314/ujah.v15i1.6
}

\begin{abstract}
Quality art education promotes emotional development, as well as cognitive achievement, which is a key factor to achieve quality education. Art education is an instrument par excellence that a nation can rely upon to bring about self-reliance. Quality art education produces positive learning outcomes, such as creating positive attitudes to learning, developing a greater sense of personal and cultural identity, and fostering more creative and imaginative ways of thinking in students. Arts-based processes allow students the opportunity to express their knowledge, ideas and feelings in ways that do not necessarily involve words. Unfortunately, the value of arts-based learning in Nigeria is diminishing because of some challenges, including the negative perception of the course by students, parents and even the society at large. It is against this backdrop that this paper brings into focus the position of the course in Nigeria's educational system with a critical analysis of challenging issues such as: the supply and training of qualified art teachers, negative attitude of individuals and government, social identity, lack of facilities and materials, among others. Recommendations were proffered on the way forward. The paper finally concludes that good quality art education is an essential component of holistic education (formal and informal).
\end{abstract}


Keywords: quality, art education, challenges, opportunities

\section{Introduction}

Art education is the process of learning about different types of artistic expression, including different media and formats for artwork and different movements and styles throughout art history (Jensen, 2001). It is commonly taught to students of many age ranges and can be a focus of learning during secondary education such as at a college or university. This type of education is usually taught by art teachers and can include practical understanding, such as how to use different tools to create artwork, or an understanding of how to appreciate artwork. Art education will usually focus on basic types of artistic creation, such as drawing, painting, and sculpture, though specialized classes in subjects such as pottery, digital art, and mixed media can also be found (Gibson, 2008).

Many art education classes will usually be split between practical knowledge and theoretical knowledge, teaching both how to create artwork and an appreciation for the work others create. An art teacher will often be an experienced artist with a background both in different types of artistic creation and teaching pedagogies. While a specialized art class in a subject such as art history could focus primarily on learning through lecture and reading, most classes will allow students to create their own artwork and view the work of others, both students and masters, to better understand artistic expression. 
While art and the creation of art can be seen as a highly subjective experience, art education seeks to find common bonds between artists and viewers. Though this may be difficult, an effort is still made to create a baseline by which art can be evaluated and critiqued. This is often done regarding technical aspects of artistic creations, such as perspective and proportion. While some works studied in art education, such as those created by surrealists or abstract expressionists, may escape easy analysis using these methods, it can still be helpful.

Students in art education are usually taught proper handling of various artistic tools, such as pencils, chalk, paint brushes, and sculpting tools. Basic art education classes will often give an overview of these different mediums and introduce students to these forms of art, allowing them to find areas where they may be interested in further study. More advanced art classes will often encourage students to pursue specific areas of interest, providing the students with opportunities to develop their skills in what they are passionate about (Eisner, 2002).

Arts education encompasses all the visual and performing arts delivered in a standards-based, sequential approach by a qualified instructor as part of the core curriculum (Garrett, 2009). The arts are both studied as individual disciplines and integrated into general subject matter teaching. The term arts education means and implies many things, it can be said to be an 
instruction and programming in all arts disciplinesincluding but not limited to dance, music, visual art, theater, creative writing, media arts, history, criticism, and aesthetics. The term is used in its broadest sense, including arts-centered and arts-integrated curriculum in academic and community settings (La Pierre, 2007).

This paper aims to ascertain why there is need for art education in our contemporary society. The emphasis on quality art education in Nigeria forms the premise of this paper. The paper discusses the importance of providing quality art education and challenges of art education in Nigeria. It also discusses the opportunities embedded in art education as an area of study.

\section{The Need for Art Education}

Beyond the qualities of creativity, self-expression, and communication, art is a type of work. This is what art has been from the beginning. This is what art is from childhood to old age. Through art, students learn the meaning of joy of work done to the best of one's ability, for its own sake, for the satisfaction of a job well done (Livermore, 2003). There is a desperate need in our society for a revival of the idea of good work: work for personal fulfillment; work for social recognition; work for economic development. Work is one of the noblest expressions of the human spirit, and art is the visible evidence of work carried to the highest possible level. Today people hear much about productivity and workmanship. Both of these ideals are strengthened each time they commit themselves to the endeavor of art. They are dedicated to the idea that art is the best way for 
every young person to learn the value of work (Davis, 2008).

Art is a language of visual images that everyone must learn to read. In art classes, visual images are made, and images are studied. Increasingly, these images affect our needs, our daily behavior, our hopes, our opinions, and our ultimate ideals (Freedman, 2003). That is why the individual who cannot understand or read images is incompletely educated. Complete literacy includes the ability to understand, respond to, and talk about visual images. Therefore, to carry out its total mission, art education stimulates language-spoken and written-about visual images. Art teachers work continuously on the development of critical skills. This is a way of encouraging linguistic skills. By teaching pupils to describe, analyze, and interpret visual images, their powers of verbal expression are enhanced (Pearse, 1992). That is no educational frill.

One cannot touch art without touching values: values about home and family, work and play, the individual and society, nature and the environment, war and peace, beauty and ugliness, violence and love (Stankiewicz, 2001). The great art of the past and the present deals with these durable human concerns. Art teachers do not only indoctrinate, but when they study the art of many lands and peoples, they expose their students to the expression of a wide range of human values and concerns. They sensitize students to the fact that values shape all human efforts, and that visual images can affect their personal value choices (Gibson, 2008). All of them 
should be given the opportunity to see how art can express the highest aspirations of the human spirit. From that foundation they believe students will be in a better position to choose what is right and good.

\section{Towards Quality Art Education in Nigeria}

Nigeria is in essence a multicultural nation. It is made up of diverse language and cultural communities that live side by side, all with their own very different but rich traditions and artistic practices (Ogbonna, 2006). This variety, and the fact that it is rooted in so many communities, is now - with the growing recognition of the importance of cultural diversity - considered to be a vital asset in the development and intellectual awakening of this country. Though this diversity was, until recently, often experienced by the populations as a weakness, reducing learning and knowledge to particular cultural values and traditions, the worldwide movement towards recognizing national and regional cultures and communities has led the government of Nigeria to contemplate the possibility of introducing cultural and artistic activities into the overall learning programme of young people, both in and outside the school (Sullivian, 2010).

People view sciences and the arts as though they were two enemy sisters. This idea is a malaise surrounding art education. In fact, though there is consensus about the fundamental nature of artistic practices for the balanced development of a human being, the prospect of setting up school curricula that promote these practices is accompanied by the fear of seeing the art education 
demoted (Marshall, 2006). Arts and sciences are considered as fields that stand apart from each other, contrary to some critics who see them as complementary.

If a person's creativity is developed by exercising a discipline, it is stimulated even more through the practical experience of art. A child discovers his or her creative potential through play and repetition, which paves the way to action and creativity. Art education, in developing young people's emotional intelligence and imagination, creates an awareness of diversity in practices and cultures as well as of their environment, which in turn makes them attentive to environmental and development issues (Pearse, 1992). This is why public programmes for art education and creative practices are chiefly aimed at children living in underprivileged or socially vulnerable milieus. Creative activities for them are a way to resist the degradation of their surroundings and their self-image. Art enables them to keep their cultural heritage alive and at the same time opens up new possibilities to be stimulated.

Teachers who are responsible for teaching arts must be at the centre of any reform in arts education, and must be able to follow the revision of the curricula step-by-step. This is an excellent way to ensure their acceptance of the proposed educational project and their competence in the various artistic fields. Great importance must be given to the training of teachers in visual arts, dance, music, theatre, etc., if the quality of art education, and thereby of school education in general, is to improve. For 
instance, the initial training of art teachers must not only take into account new teaching methods that emphasize the creativity and traditional know-how of the community, but also the use of electronic tools as a means of artistic production and learning and a source of knowledge that can no longer be ignored.

In the case where generalist teachers, who do not necessarily master the subject, have to teach the arts, it is suggested that they choose an artist to work together with them in the class. It seems important, however, to define the profile of teachers both in primary and secondary school, as well as in extracurricular art activities. The question must be asked, when should artists participate in the teaching, and whether one must speak of teaching artists or artist teachers, or both. The main purpose of art education is not only to train artists, but to kindle aesthetic sensitivity in the child and the adolescent, to initiate them to the practices and language of the arts and to develop their creativity (Obiora, 2006). Generalist primary-school teachers must be able to receive adequate training in at least two art disciplines, of which the standard could be defined on a national level. In addition, teaching support can be given by professionals from cultural institutions (music centres, museums, theatres, etc.) and/or artists.

It is essential on each school level to define an educational project that will be implemented in partnership with a cultural institution chosen by the school. More importantly, since one of the learning methods in art subjects is to encourage the student to do 
research the teacher's own knowledge becomes of secondary importance in the knowledge-transmission process (Gibson, 2008). This method, in fact, downplay the knowledge of the teacher - in particular in terms of the students' behaviour- and is based on the students' desire and intentions towards the artistic object. In as far as possible, it limits the giving of instructions, promotes the students' autonomy and respects their critical ability.

Art education that initiates children and adolescents into artistic techniques and language, builds cultural identities and reinforces self-confidence and respect of the other and his culture (Sophia, 2005). In this way, it also opens the door to multiculturalism. In order to introduce the child to the practical experience of art and its diverse expressions, art education must look at both traditional expressions of art and those developed on its contemporary side. It is at the intersection of these two cultural reference fields that the child evolves within his or her community (Sophia, 2005). Cultural institutions such as museums, music centres, culture centres, theatres and cinemas as well as craft centres are all places that must be promoted. They must be able to contribute to the educational effort of each nation and more specifically to the education of the arts.

Another rich source lies with artists themselves: dancers, actors, musicians, poets, writers, painters, sculptors and craftspeople all have undeniable skills in terms of creativity, action and reflection. They are the gobetweens from one artistic tradition to another. They are also the living memory of a community's art and culture 
and the magicians that transform these traditions into future memory. Their role in a quality arts education is evident, but the ways in which they could participate still need to be defined.

\section{The Importance of Providing Quality Art Education}

Art is one of the universal languages all human beings understand and use to communicate. We use art to understand who we are, our places in the world, and the meaning of our lives (Burton, 2000). We use art to express ourselves and to speak to others across time and place. Human beings have an essential drive to create and understand visual imagery. This drive is one of the basic traits that make us human. The importance of providing quality art education in our society can be deciphered from the significance of many dimensions of art education, though the emphasis in this context is on visual arts. The power of the visual arts to enrich human experience and society is recognized and celebrated throughout the world.

Art and the visual arts are part of the historical record of every culture and historical period known to human beings. It may be said that all we know about some past civilizations is found entirely in the record of art and artifacts that people left behind. The visual arts have been used to capture and express a wide array of values, beliefs, and ideas embraced by people from around the world and from every period of history (Sophia, 2005). The visual arts have been used to educate, persuade, commemorate, and solve problem, in fact, humans are 
dependent upon the visual arts to make sense of the world in which they live daily.

Individuals are continuously inundated with innumerable visual images and messages on television, computers, digital communications devices, and in the printed media. Neuroscience has shown that a significant portion of the human brain is devoted to understanding visual stimulation and to decoding visual messages they receive through their sense of vision (Eisner, 2004). They do this by using all of their higher order thinking skills, memory, and education. In our contemporary society, the visual arts and dependence upon visual imagery is essential in communicating and understanding information we need to live our lives. In order to fully understand visual imagery and its meaning, it is essential that all people receive an arts infused education. Such an education enables people to become informed citizens, critical thinkers, creative problem solvers and productive members of society.

At a time of economic challenge in some countries, many school districts have been forced to make difficult decisions that have decreased or eliminated visual art education from their schools. Despite a growing body of evidence suggesting that students who have had instruction in the visual arts perform higher on standardized tests and other measures of educational performance than those who have not had such instruction, art education programs continue to be overlooked for the contributions they make in producing the highest quality of education required for all children 
(Hafeli, 2000). One of the hallmarks of quality visual art education is its focus on creativity. Students in art classrooms at all instructional levels are routinely called upon to use their creativity to solve problems and to express their ideas. Art teachers are steeped in the knowledge and skills that foster creativity and they use the visual art curriculum to enable their students to explore their own creative powers. Nurturing and developing students' creative capacities are vitally important for advancement in the workforce and for maintaining Nigeria's leadership role in Africa.

\section{Differences between teaching visual arts and teaching art Education}

Visual arts students are thought to exhibit work as practicing artists and they have a more liberal degree and can apply their experience to a very broad range of careers related to the visual arts. Those with visual art degrees plan on becoming practicing artists and designers in their field. Additionally, they may pursue graduate studies and become qualified to teach at the college level. Art education focuses on preparing preservice teachers for a profession in art education. Through supplemental courses, pre-service teachers also may prepare for positions in museum education and other non-profit visual arts applications or for graduate study. Art education is not limited to formal education institutions, some professional artists specialize in private or semi-private instruction in their own studios. 


\section{Challenges of Art Education in Nigeria}

If quality art education excel, it will contribute to poverty alleviation and the sustainability of social and economic development of the nation via job creation. However, realistic as this may be, there are inherent problems that art education is facing in its development. Notable among them are: shortage of qualified art teachers, inadequate teaching facilities and funding, poor government and social identity. Although the National Policy on Education (2004) has recognized the teaching of art at all level of education, the subject is faced with shortage of the supply of qualified art teachers (Cornelius, 2004; Barnabas, 2005). There is the need for a deliberate and purposeful training of art teachers for the nation's school system. There are many schools that do not have qualified staff to teach art.

The other problem areas affecting art education, is inadequate teaching facilities. Research in art education (Gofar, 2000; Barnabas, 2005), shows that, most schools are faced with the issue of lack of art materials and purpose-build art studios in secondary and colleges of education for the teaching of art. Because of the facilities not available, the teaching of art is at best an exercise in futility. The student-artist cannot acquire artistic skills without the materials.

Another factor that constitutes problems in the learning, and teaching of art in Nigeria, is the ambivalent negative attitude of Nigerian society and event the government towards the subject. This situation has created for teachers of art a serious dilemma of reconciling an 
already falling standard of education. Mbahi (2000) noted that, there is the misconception in the society that because art is a practical work and not academic, that art teacher is inferior in personality and should not claim the same status with his colleagues in the academic areas. This has affected enrolment in art teaching. It has also leads to the non-availability of trained art teachers with requisite experience. Also, the lack of recognition of the subject of its importance by the populace and even the government is another problem facing the subject.

The issue of social identity is another problem in terms of material value and position in education. Many students and parents see the subjects in terms of material value. Issues like personal interest, attitudes, types of education attained, one's life style and capabilities are ignored. Subjects like medicine, science, engineering, among others are therefore considered by students and parents (Mbahi, 1999).

There is the problem of inadequate curriculum planning and development. We are in the age of computer and information technology that require a complete reformation or reviewed of school curriculum. Art programmes at all levels of education need this review of curriculum. Many of those who participate in curriculum planning are not educationists but subject specialist. Curriculum specialists should be given the chance to review curriculum. 


\section{Opportunities of Art Education in Nigeria}

Those who have obtained an Art Education degree have an understanding of the procedures and development of the art processes. In addition to this, those who are looking for a job with this degree will be equipped to understand how students learn and process information. Individuals who have an Art Education degree will be able to make a connection between art and history, art and emotion as well as art and life in their careers. The ability to make these connections will enable them to be more effective as they introduce art to their students. Introducing high school students to art and how it connects with the world is a job that is rewarding to many who have an Arts Education degree. Guiding students to express themselves through art provides art teachers a way to create value for aesthetics. According to Hilary (2006) high school teachers earn between N400.000 and N600.000 a year. Secondary teachers have to obtain proper certification before they are able to teach in schools. Those who are interested in teaching high school students should check with the school district to ensure that they have proper certification.

Opportunities are available for those with Art Education degrees at post-secondary institutions. Applying to a community college may open doors to start a career in art education. A job seeker may consider becoming a contract teacher for the Art Department at a local college or University. Contract positions can eventually lead to a more permanent position. Art instruction at a local community college or university may include subjects such as art history, art and culture and beginning 
Okonkwo: Towards Oualitv Art Education: Challenges and Onnortunities

drawing. Teaching at a post-secondary institution is more flexible because classes do not meet everyday. According to Hilary (2006), post-secondary teachers in Nigeria earn between $\mathrm{N} 900.000$ and $1.2 \mathrm{M}$ a year. Consideration should be given to the possibility of running a private art teaching studio. The art teacher who works from his private studio can offer instruction to children who are just beginning to become interested in art as well as adults who want to try a new skill. Flexibility to choose class sizes as well as how large or small the classes will be is an advantage that this kind of teacher has. Private lessons can also be given art studio. If a person decides to work from a private teaching studio, he should decide whether he prefers to work from home or to work from rented space. He should check with his local zoning office to ensure that working from his home is an option (Anderson, 2002).

\section{Recommendation}

To achieve a quality art education at all levels of education, government, private organization, parents, individuals and all stake-holders in the national educative process should jointly work to provide whatever human, material and financial resources to ensure improved quality art education programme. The following recommendations arising from the forgoing discussions will go a long way towards a quality art education and also make art education a viable vehicle for self-reliance in the $21^{\text {st }}$ century.

1. Shortage of manpower has restricted many schools from introducing art in their schools, 
Government should supply and keep effective qualified art teachers at various levels by giving special inducement grants. The current number of art teachings should be doubled more especially at NCE level of intake in art courses.

2. Indicators of a conducive teaching-learning environment are: attractive physical structure of studios and classroom, supply of art materials at any given times. Availability of variety of art materials helps both art teachers and students develop lifelong skills.

3. Review of the art programmes at all levels of education because we are in the age of globalization. Art education (fine and applied arts) need to quickly and rapidly respond to the changing needs of the society and the demands of the global realities and also to guarantee survival and competitiveness. This should be done by curriculum specialist not subject specialist.

4. Increase funding of art education: This should be done in the area of special incentives to the teachers, supply of art materials and equipment.

5. Increase the supply and training of qualified art teachers at all levels of education: It is time that without high quality art teachers in the right quantity; no appreciable progress can be recorded. Therefore, efforts should be made to increase, the rate of training and retention of art teachers. 


\section{Conclusion}

Art education is a part of school education that focuses on a wide range of arts, such as painting, drawing and sculpture. When looking at a subject like art education, there are opinions about whether it is a good skill for schools to teach or whether it is unnecessary and a waste of money. The course has many problems that arise as a result of differing opinions. Art education as an area of study has many challenges because its importance is not always noticeable. The thoughts that arts are unnecessary are one of the main challenges art education faces in society. Art education has a problem with emotional expression in many schools. The art of past generations was filled with emotion and passion. Unfortunately, modern art styles, that are often abstract, can make it difficult to determine emotions in art. This lack of focus on feeling and expression in the art education programs can remove the creativity and expressiveness from the art.

Good quality art education is an essential component of holistic education (formal and informal). It enhances self esteem, a sense of identity, unity and diversity. It improves the ability to handle change in a dynamic society. It encourages an appreciation and understanding of heritage. It enables the creation of future heritage, design and production. It increases individuals' potential to make a living, be more creative in the workplace and improve achievements in other spheres of life. Art education encourages freedom of expression and enriches the child's creative and 
imaginative self. It also improves linguistic skills and stimulates social responsibility and spiritual growth.

Ivan Emeka Okonkwo is of the Department of Fine \& Applied Arts, Nnamdi Azikiwe University, Awka, Nigeria.

\section{References}

Anderson, T. (2002). Real lives: Art teachers and cultures of school. Portsmouth, NH: Heinemann.

Barnabas, S. D. (2005). Teachers' assessment of children creative artwork: Case study of some primary schools in Kaduna State. Unpublished M. A. Thesis, Department of Fine Arts, A. B. U., Zaria.

Burton, J. M. (2000). Learning in and through the Arts: The question of transfer. Studies in Art Education, 41(3), 228-257.

Cornelius, H. D. (2004). An investigation into the teaching of art in some selected secondary schools in Tafawa Balewa L. G. A., Bauchi State. Unpublished Undergraduate Project, Department of Fine Arts, A. B. U., Zaria.

Davis, J. (2008). Why our schools need the Arts. New York: Teachers College Press and Reston, VA:

National Art Education Association.

Eisner, E. (2004). The arts and the creation of the mind. New Haven: Yale University Press. 
Federal Republic of Nigeria (2004). National policy on education, $4^{\text {th }}$ edition. NERDC Press. Yaba, Lagos - Nigeria.

Fiske, E. (Ed.) (1999). Champions of change: The impact of the arts on learning. Washington DC: Arts Partnership \& President's Committee on the Arts and Humanities.

Freedman, K. (2003). Teaching visual culture. New York: Teachers College Press.

Garrett, P. (2009). Arts in Australia's national school curriculum. Canberra: Office of the Minister for the Environment, Heritage and the Arts.

Gibson, R., \& Anderson, M. (2008).Touching the void: Arts education research in Australia. Asia Pacific Journal of Education, 28(1),103-112

Gofar, D. N. (2000). Measurement of the relationship between continuous assessment score and performance in art. Unpublished M. A. Thesis, Department of Fine Arts, A. B. U., Zaria.

Hafeli, M. (2000). Negotiating "Fit" in student art work: Classroom conversations. Studies in Art Education, 41(2), 130-145.

Hilary, M. B. (2004). An evaluation of art programmes in some selected secondary schools in Taraba. Unpublished M. A. Thesis, Department of Fine Arts, A. B. U., Zaria.

Jensen, Eric (2001). Arts with the Brain in Mind. Alexandria, Virginia: Association for Supervision and Curriculum Development. pp. 57-58, 81. ISBN 0-87120-514-9.

La Pierre, S., \& Zimmerman, E. (2007). Research methods and methodologies in art education. 
Reston, Virginia: National Art Education Association.

Livermore, J. (Ed.) (2003). More than words can say: A view of literacy through the arts. Canberra: National Affiliation of Arts Educators.

Mbahi, A. A. (1999). Art teacher. Kingswell Publishers Ltd., Maiduguri.

Mbahi, A. A. (2000). Art teacher. Kingswell Publishers Ltd., Maiduguri.

Marshall, J. (2008). Visible thinking: Using contemporary art to teach conceptual skills. Art Education, 61(2), 38-45.

Obiora, J. (2006). Substantive art integration: exemplary art education. Journal of Art Education, 59(6), $17-24$.

Ogbonna, K (2006) Multicultural Citizenship and Diverse Culture in Nigeria. Oxford University Press: 2006 p.3

Pearse, H. (1992). Beyond paradigms: Art education theory and practice in a postparadigmatic world. Studies in Art Education, 33(4), 244-252.

Stankiewicz, M. A. (2001). Roots of art education practice. Worcester, MA: Davis Publications, Inc.

Sophia, J. (2005). Connecting art, learning, and creativity: A case for curriculum integration. Studies in Art Education, 46(3), 227-241.

Sullivan, G. (2010). Art practice as research: Inquiry in visual arts. (2nd ed.) Thousand Oaks, CA: Sage Publications. 